\title{
The Political Economy of Education Research
}

\author{
CHAD LYKINS \\ University of Hong Kong
}

Government agencies and professional organizations have attempted to improve education research by creating common standards for judging research quality. However, the absence of agreement regarding research quality has limited the effectiveness of this approach. This article argues that, rather than focusing on standards, policy makers should leverage the market-like behaviors of those engaged in education research by influencing the incentives that drive them. Drawing on political philosophy and social theory, I argue that governments should focus less on standards and protocols and more on reforming the processes by which research capital is distributed.

\section{Introduction}

Recent efforts by government agencies and professional organizations to improve education research have focused on creating common standards for judging research quality. In the United States, the standards-based approach has yielded numerous pieces of legislation, such as portions of the Reading Excellence Act (REA 1999), No Child Left Behind Act (NCLB 2001), and Education Sciences Reform Act (ESRA 2002). It has also produced a series of National Research Council (NRG) publications, including Scientific Research in Education (NRG 2002), Strategic Education Research Partnership (NRG 2003), and Advancing Scientific Research in Education (NRG 2004). Recently, the American Education Research Association (AERA) has offered its own statements on standards (AERA 2006, 2008, 2009). In the United Kingdom, a similar debate continues to rage, centered initially on the publication of a series of reports (Hargreaves 1996; Hillage et al. 1998; Reynolds 1998; Tooley 1998) aimed at improving the standards for rigor and relevance in education research.

These efforts suggest that policy makers are increasingly concerned with the governance and finance of education research. Federal agencies are seeking 


\section{Political Economy of Education Research}

to regulate both how research is consumed (e.g., what counts as "scientific" evidence of program effectiveness), as well as how research is produced in federally sponsored research programs. However, their efforts to create enthusiasm for common scientific standards have been highly controversial. If anything, divisions over the nature and purposes of education research are now more pronounced than they were before the last 15 years of standardsetting. One positive benefit of this is increased scholarly attention on what education research is and what an education research community should exemplify (see, e.g., Atkinson 2000; Biesta 2007; Clair and Belzer 2007; Crossley 2008; the special issues of Educational Researcher 2002; or the several booklength treatments of the subject, such as those by Baez and Boyles 2009; Hess 2008; and Johanningmeier and Richardson 2008). Several of these authors are responding directly to federal reports and legislation, challenging them on philosophical, scientific, and political grounds.

There seems to be a broad, though not universal, sense that the federal government should focus its support on "rigorous" research. However, the meaning of rigor is subject to "contestation and change" (Eisenhart and Towne 2003). Federal agencies tend to identify rigor with adherence to protocols or standards. The authors of the influential NRC report, Scientific Research in Education (NRC 2002), identify rigor with adherence to general principles. Cannella and Lincoln (2004) argue for a more expansive definition of rigor that would include "continued use of reflexive critical ethics, open and constant public communication ... the appreciation of and support for intellectual diversity . . . contextual (sometimes even historical) knowledge, and critical actions" (305-6). Though they work toward different conclusions, each of the above-mentioned parties starts from the assumption that one can state a priori the characteristics of good research. These characteristics (whether they are in compliance with standards, or endorsement of principles, or political commitments to justice) are then presented as something prior to and external from the actual process of inquiry. It is either a checklist of methodological and design requirements, as in legislation, or a checklist of epistemological, political, and ethical orientations. What both approaches have in common is the conviction that we can say at the outset, before inquiry has been conducted, what the conditions of good inquiry are.

These approaches are threatened by the market-like behaviors of those en-

CHAD LYKINS is assistant professor of philosophy and education policy in the Faculty of Education at the University of Hong Kong. His research includes philosophical scholarship on education, public policy, and the social sciences; empirical investigations in the finance, governance, planning, and evaluation of education research across different national contexts; and research, development, and evaluation of educational programs. 
gaged in education research. That is, they depend on the existence of a community of ethically upstanding individuals in order to succeed. However, it is not clear that such a community is any more likely to emerge among education researchers than among media corporations or automobile factories. The market-like behaviors of individuals do not cease to exist once those individuals become researchers. Thus, it should not be seen as surprising or anomalous that researchers seek not just truth or the liberation of human beings from suffering, but more banal goods like citations, grants, tenure, promotion, and fame. What is needed is a model of research that can somehow leverage these more banal pursuits into something that serves broader public ends.

This article gives such a model. It is modest in comparison to the abovementioned authors in that it does not purport to state the necessary and sufficient conditions of rigor in education research. Instead, it attempts to shift the debate from what rigorous research is to a debate over the political and economic conditions that make rigorous research possible. While it does offer an account of rigor in education research, this account is procedural rather than substantive. That is, it claims that rigor is a characteristic of the process by which research is produced and consumed, not the substantive ethical, political, or epistemological assumptions that it makes. The key factor in this process is the presence of criticism by diverse, self-interested rivals. Thus, the marker of a good research community is not whether it stays true to standards set down prior to inquiry but the extent to which it makes such criticism central to its operations. However, the degree to which this kind of criticism is present is, in part, a function of the economic and political environment in which researchers find themselves. This means that governance of education research can and should work from actual political and economic conditions, rather than from an idealized vision of what their values and beliefs ought to be or a vision of what protocols they ought to adopt.

Rather than turning to theories about research quality, the article turns to research in political philosophy and social theory to outline the main features of the political economy of education research and how they can be usefully attended to by government. It argues that researchers exhibit market-like behaviors, being influenced by various incentives that can, in turn, be manipulated by government interventions. Rather than coercing adherence to external standards, government interventions should leverage the competing interests of those engaged in education research. Drawing on the work of Elizabeth Anderson and James Bohman on the conditions of democratic deliberation and of Pierre Bourdieu on the economics of scientific inquiry, it argues that government should act to increase the incentives for researchers to undergo critical engagement with those who have an interest in showing the weaknesses of one's own research. Critical engagement of this kind makes 


\section{Political Economy of Education Research}

it possible to acknowledge deep social, political, or economic influences on research while still carrying the possibility of transcending these idiosyncrasies.

\section{Overview}

The article proceeds as follows. In the first section, I argue that education research can be seen as a form of political and economic activity by examining the market-like behaviors of those engaged in education research. In the second section, I show that, like other political and economic activities, both the regulatory approach embodied in standards-based reform and laissez-faire approach advocated by many critics can produce undesirable consequences. In the third section, I argue that the source of these undesirable consequences lies in the distinctiveness of the way capital is distributed in education research and other criticism-based fields of economic activity when compared to other fields of political and economic activity. I then argue that these consequences can be avoided by acting so as to promote the unique economic character of inquiry and minimizing the extent to which other forms of capital seeking are profitable.

\section{The Political Economy of Education Research}

\section{The Political Economy of Education Research}

This article examines the role of government in the political economy of education research, a term I use to refer to the people and institutions engaged in the production, consumption, and exchange of education research. Since others have used this term for somewhat different purposes (Clair and Belzer 2007; Crossley 2008), I will take some space to clarify how exactly the term is used in this article.

Education research.-The meaning and purpose of education research are themselves matters of sustained debate (Eisenhart and Towne 2003; Johanningmeier and Richardson 2008, 59-79). This article does not intend to take sides. To the extent that it violates this intention, it takes the side of inclusiveness rather than exclusiveness. The account it gives extends to "research" broadly conceived so as to include the physical sciences, social sciences, humanities, and arts. It includes activities such as reflection, speculation, observation, analysis, argument, and synthesis (for a similarly broad definition, see Mortimore 2000).

The article takes the same inclusive approach to understanding the distinction between education research and other research. Education researchers 
borrow topics, questions, methods, and techniques from a wide range of disciplines, notably, economics, sociology, anthropology, philosophy, history, medicine, epidemiology, and studio art. Given this wide range of resources, it seems that any distinction that focuses on a specific methodology or tradition is unlikely to succeed. For the purpose of this article, "education research" refers to inquiry into the various factors that influence and are influenced by the creation of beliefs, attitudes, dispositions, habits, values, abilities, and skills. (This definition is admittedly broad, especially in that it makes no effort to distinguish intentional vs. nonintentional creation. I think the distinction between the two is less clear than is assumed by others, such as Cremin [1976] or Loewenberg Ball and Forzani [2007]).

Production.-Education research is produced by individuals, often in their institutional roles within universities, schools, think tanks, private firms, nonprofits, popular media, as well as local, state, and federal agencies. Both the processes and products associated with this production vary. The processes may involve (for example) calculation, data collection, grant seeking, observation, reflection, and reading. These processes may yield a variety of products, including blogs, books, documentaries, editorials, journal publications, monographs, presentations, reports, testimonies, as well as more imaginative goods.

Consumption.-These various research products are consumed by students, parents, teachers, principals, administrators, politicians, bureaucrats, program officers, and the producers themselves. For instance, students may make use of research comparing universities when deciding where to pursue their degree. Parents may use research on student outcomes to inform whether to send their child to a public or private school. Principals have been found to use research to inform a wide range of decisions (for positive examples, see Biddle and Saha 2002; for less sanguine examples, see Spillane [2004]). Legislators use research to inform and justify policy positions (for an interesting example of the use of research to justify charter school policy, see Henig [2008]). Producers may consume research so as to know the latest developments in their fields. Different consumers may prefer different qualities in research products - for instance, products that align with a certain disciplinary, political, or ideological paradigm; research products that can be consumed quickly; or research products that are narrowly or broadly focused. These preferences may be influenced by a number of factors, some of which are discussed later.

Exchange.-Exchange refers to the process by which education research products reach education consumers. Others have argued that this exchange bears sufficient similarities to other markets to warrant speaking of an "education research market" (Clair and Belzer 2007; Crossley 2008). Some products reach a large number of consumers, while others remain niche artifacts. Part of the difference may lie in the inherent qualities of the research products. For instance, a technical journal article may, due to its complexity, never directly reach a 


\section{Political Economy of Education Research}

wide audience, while a succinct policy report on the same topic might have a more diverse constituency. However, many factors that affect exchange are extraneous. For instance, clearinghouses (such as the What Works Clearinghouse) and indexes (such as the Web of Science) may have a significant difference in the volume of exchange for various research products.

Political economy. - By referring to the economy of education research, I mean to draw attention to the means by which it is produced, consumed, and exchanged. This economic activity is political insofar as it involves "the authoritative allocation of values" (Easton 1965, 50). It affects the ways people think of the aims and values of education, as well as the means for achieving them. There is an indefinite number of possible research questions, as well as an indefinite number of ways of going about answering them. Yet only some attract the resources necessary to pursue them further. Inevitably, the questions valued by some parties will attract greater attention, as will answers that tend to benefit some rather than others. Thus, in addition to being an economic activity, education research is an inherently political activity.

Capital. - The decision to produce, consume, or exchange education research requires an investment of capital. The capital invested is not always or even primarily financial. The investment may be in the form of social, cultural, symbolic, or intellectual capital (see Bourdieu [1986, 1991], though he would likely include "intellectual" capital as a subspecies of cultural capital). Social capital can be roughly conceived of as the durable relationships an agent has with other agents. These relationships can be used to acquire various goods and to establish one's status in a group. Cultural capital consists of the various attitudes, beliefs, and manners that signify his or her social status. Symbolic capital consists of the ways that others classify an agent (e.g., as "lay" or "expert"). Intellectual capital refers to an agent's cognitive and affective resources.

Profit.-The primary incentive for making such an investment is the expectation of profit. Profit can be seen as the amount of capital returned to the agent in excess of his or her investment. For instance, a university faculty member may leverage her social capital to form a team of researchers. This may allow her to create research products that yield higher rates of return than if she were to work alone. The returns might come in the form of social capital (deepened or widened social networks), symbolic capital (citations, tenure, and promotion), or intellectual capital (skills and abilities). The expectation of profit may also influence her choice of which journals to read, grants to seek, and students to mentor.

The notion that individuals seek profit requires two important clarifications. The first is that they need not seek the highest profits possible. While classical economics posits that agents seek maximum returns for minimal investments, recent work suggests that they merely seek a reasonable or satisfactory return 
(Feuer 2006). The second clarification is that it does not matter whether one sees the expectation of profit in the form of "doing good" or "doing well," that is, one's effect on others or one's own well-being. For instance, a person may invest in research without the expectation of any private rewards, expecting some public benefit instead. However, the ability to do research that contributes to the public good is dependent on the same economic maneuvering as the ability to do research that contributes to one's private wealth. In both cases, producers must learn which research projects are considered "marketable," that is, which projects are sufficiently in demand that the producer can attract investors. This requires that the agent gains entry into a competitive market and accumulates financial, social, cultural, symbolic, and intellectual capital.

Competition.-As in other spheres of economic activity, agents in the education research market compete against one another for scarce resources. Success depends to some extent on the ability to outperform others through the appropriation of relatively high returns for relatively low investments. In a research economy, the returns for any given investment are determined by those who consume the work. This enforces a unique form of market discipline. This discipline occurs through the system of "crisscrossing checks and balances" from other producers and consumers of education research (Bourdieu 1991). In a well-functioning research economy, the profits sought by education researchers - research grants, publications, tenure, and so forth - can only be acquired by submitting their work to the criticism of well-armed, similarly self-interested parties. These self-interested parties have a vested interest in framing their rivals' efforts as inadequate or incomplete. If they can demonstrate that the research is significantly flawed, they can improve their own position in a competitive market. If they cannot put forth such a public demonstration, then the producer of the research product is able to appropriate whatever capital is at stake.

This view of education researchers as economic agents may seem a bit jarring or overly cynical. However, it has the following benefit over the "hagiographical" view of researchers as objective inquirers: it is compatible with the more cheerful view of research without necessarily requiring it. That is, even if humans are the power-hungry, self-interested scoundrels described by Adam Smith and Michel Foucault, their self-interested power seeking can still be used to produce research that transcends these limitations. Parochial loyalties to one's class, party, or nationality are likely to be exposed by those with loyalties to contending factions. On Bourdieu's view, this is meant to explain how exactly scientific inquiry - and, to a great extent, humanities and artsbased inquiry - can achieve objectivity even if researchers themselves are influenced by values. But this objectivity is possible only when the acquisition of capital is dependent on surviving public, free, generalized, and diverse 


\section{Political Economy of Education Research}

criticism from self-interested rivals (Bourdieu 1991, 22). Regardless of whether this yields "objectivity" in the strong sense, I offer as a hypothesis that it tends to generate inquiry that is more rigorous and relevant than that which is produced through some other economic processes.

The problem then is that researchers need not limit their profit seeking to this sort of public competition. Like firms in other economic spheres, agents can affect the perceived value of research products through practices such as marketing and lobbying. These practices can work to undermine the role of criticism as the sole conveyer of capital. If this happens, the various struggles to gain market position among researchers lose the potential to transcend the narrow interests of each party. The rigor and relevance of education research depends on the extent to which the research economy distributes capital according to critical versus noncritical competitions (Bourdieu 1991, 20).

Procedural constraints. - Education research, in addition to being a political and economic activity, is a form of inquiry. As in other forms of inquiry, the value of any given investment in education research is unclear in its beginning stages and often no more transparent upon its completion. The difficulty in assigning a value to education research confuses decisions as to appropriate investments. For instance, a program officer at a grant-making agency may be unable to forecast which topics, questions, and methods are most likely to yield the highest returns on investment. Given this lack of information, agents are more likely to seek a reasonable rate of return rather than an optimal one. These cognitive limitations do not affect only education researchers but all agents involved with education research - students, parents, teachers, administrators, superintendents, program officers, politicians, as well as the institutions through which they function.

Goldhaber and Brewer (2008) describe how these procedural constraints can be exploited by those seeking alternative methods of pursuing capital. They hold that consumers "have little knowledge of what constitutes sound research design," but they often have a clear idea as to what they would prefer for a study to conclude (199). This means that nuanced findings may have no "natural constituency" (213). Researchers then have an incentive to pick research approaches that will give results, "that fit a popular ideological perspective" (199). In addition, the ability to reach these consumers through popular media increases the incentive to focus on publications that are meant for popular consumption, rather than "the establishment of a scholarly track record" (199). On their view, these perverse incentives have caused the market to become flooded with research, allowing consumers to pick products that serve their preconceived tastes (201).

Efficiency.-There are at least two ways of thinking about efficiency regarding education research. The first considers the political economy of education research as a whole, holding that efficiency occurs when additional investments 
in education research produce a less satisfactory return than investments in some other market sector. For instance, assume that total investments in education research could be converted into dollars, currently equaling $\$ 100.00$. Now assume that an additional dollar spent on education research can be expected to return only $\$ .50$, whereas an investment somewhere else (say, medical research) can be expected to return $\$ 2.00$. Under these circumstances, additional investments in education research would produce less satisfactory returns than additional investments in medical research.

The second way of thinking about efficiency concerns the distribution of investments within education research, holding that efficiency occurs when a change in the way investments are distributed within the education research market would produce outcomes of equal or lesser satisfaction. To illustrate, assume that there is $\$ 100.00$ worth of capital invested across five kinds of education research, labeled ER1, ER2, ER3, ER4, and ER5. It may be the case that these different kinds of education research have different returns. For instance, say that ER5 consists of using phrenological data (information about the size and shape of the skull, widely gathered in the nineteenth century but now understood to be politically and scientifically reproachable) to predict gum-chewing activity among protestant fifth graders. Producers will likely see that investments in ER5 are unlikely to yield satisfactory returns (public or private), resulting in wasted financial, social, cultural, symbolic, and intellectual capital. Any distribution of capital that allocates resources to ER5 will likely be less efficient than one that does not.

However, such obvious cases are not typical. The choices are more often between contenders with reasonable claims to legitimacy, such as between grade levels, academic subjects, methods, outcomes, and so forth. If we propose that supply and demand serves as the sole mechanism for distributing capital among competing types of research, we might expect producers to be able to form a plausible interpretation of their current market position and the relative value of different investment strategies.

For instance, a doctoral student would understand the likely impact on her chances of securing a job of writing a dissertation in philosophy of education rather than secondary data analysis, or social studies rather than physical sciences, or secondary rather than tertiary education, or any of the many topics within these categories (i.e., she would know what is "hot"). In addition to these categorical differences, she would understand the impact on her rates of return of the quality of her work or, more precisely, how others perceive the quality of her work. She would be interested in making sure her work is perceived as being of high quality relative to her competition. If supply and demand was to function as the sole mechanism for distributing capital among researchers, we would expect producers to pursue research that is "hot" (i.e., relevant) and is perceived to have high quality (i.e., rigorous). In an efficient 


\section{Political Economy of Education Research}

distribution, no category of research would stay too hot for long, for this excess demand would soon be met with appropriate supply. Further, no category would be especially burdened by research perceived to be of low quality, as opportunistic newcomers would come to drive it out.

Market failures.-The market for education research can fail to be efficient in at least three ways. The first is that agents may find alternative mechanisms to open competition to generate returns for research products. This is made possible because the value of any given research product is difficult to ascertain, especially given that it must often be paid for in advance of its actual execution. Rather than having the value of research products fixed through free and open criticism by self-interested opponents, they may be able to disarm their opponents through lobbying, marketing, or some other means. Thus, the actual value of these products may be different than the value producers realize.

According to Goldhaber and Brewer (2008), the "public monopoly" of K12 education makes it easier for producers of education research to avoid criticism from education consumers (214). Due to a lack of competition, there is no form of market discipline to encourage consumers to "use research-tested education strategies and to demand better research" (215). If this monopoly was dissolved, education providers would have a greater incentive to distinguish research that is actually relevant to improving student outcomes.

Another way of avoiding competition is by controlling who enters the market. If the "wrong" kinds of producers are granted entry, they can flood the market and negatively affect the perceived value of research products. In a well-functioning market, barriers to entry take the form of unrelenting criticism. That is, each agent works to expose the ethical or epistemological flaws of his or her opponents. This benefits consumers by improving the overall quality of research products. However, in a dysfunctional market, producers manipulate the value of their research projects by erecting extraneous barriers to entry, ones that serve no purpose other than to shield them from the criticism that might threaten their own market position.

The second way the market for education research can fail is if agents can successfully divorce themselves from negative externalities associated with their products. The collection of student data may be a worthwhile example. A great deal of research requires students to suspend the activity of learning in order to be assessed and to prepare to be assessed. The researcher may not be responsible for any harms associated with the lost opportunity. Similarly, the costs of failed intervention studies may be borne unevenly. A failed intervention may have a highly positive rate of return for a researcher yet extremely negative consequences for the subjects involved (this possibility is what motivates the strident arguments against experimentation in education by Baez and Boyles [2009]). More subtle examples of negative externalities are also possible. 
The third way that the market for education research can fail is if an agent's private interests are misaligned with the public's interests. For instance, agents may experience higher returns conducting cross-sectional research than longitudinal research. The time and effort involved in longitudinal research may jeopardize a producer's chance of tenure and promotion. Further, consumers may find that the results come in too late to serve their purposes (such as demonstrating success on one's campaign promises, or choosing a career). However, there might be returns to such research that, though not captured directly by the producer and consumer, are diffused throughout society. Such justifications are often used to support public investment in essential public services, such as security and transportation. They may also justify public investment in education research.

This tension is made even more evident when traditions of academic freedom are pitted against public accountability. Johanningmeier and Richardson (2008) find evidence that at least some education researchers directly respond to shifts in federal priorities, apparently willing to trade self-direction in exchange for contract-based grant work. However, many are willing to sacrifice the external funding necessary for expensive projects in exchange for the preservation of their autonomy. According to Goldhaber and Brewer (2008), the autonomy of academics means that much research may be "fragmented, disparate, and parochial," or focused on "narrow problems" (209). Furthermore, they claim that the dominance of education schools by qualitative researchers leads to overproduction of "small, fragmented studies that focus mainly on process, rather than on large, definitive studies that emphasize outcomes" (209-10). In their view, producers should not have such a large influence on what gets produced, as they are neither sufficiently "attuned to the needs of the field" nor in possession of "high-quality standards."

\section{Three Approaches to the Education Research Market}

At the most generic level, government interventions can manipulate the rates of return for various investments in education research, thus changing the way that agents perceive the alignment between certain decisions regarding research and their own interests. For instance, assume the market does not on its own generate sufficient incentives to engage research on a given topic. Producers may lack incentive because there are few tenure track jobs available, few journals that dedicate pages to the topic, and no grant-making agencies interested in it. Consumers find that the financial and human resources needed to engage research on the topic outweigh any reasonable expectation of benefits.

Let us continue to assume that such research - if it existed - may significantly benefit the public. Such an instance might warrant government inter- 


\section{Political Economy of Education Research}

vention. The government might create a national center for the study of the topic, provide seed money for a journal, and subsidize the education of those who are interested in research on the topic. It could also create a clearinghouse of information so as to help consumers gain easier access to research on topics of interest.

There are at least three possible government responses to market failures. The first is the laissez-faire approach, which holds that though the market may not be perfect, any government response will in the long run make it even less perfect. The second is the standards-based approach, which holds that the market can be improved by stimulating allegiance to a set of standards issued by government or professional bodies. The third approach is the criticism-driven approach, which holds that the market can be improved by increasing the incentives to subject one's inquiry to the well-armed criticism of one's rivals. In the following pages, I describe in more detail (1) what each approach is, (2) the logic of how it works, and (3) the main reasons why it may fail. I show that though all three approaches are imperfect, only the criticism-driven approach allows for the possibility of self-correction.

The laissez-faire approach would seek to maximize the free movement of capital between and among producers and consumers of education research. Under such a system, government subsidies for the production and consumption of research would cease to exist. On a very strict interpretation, government subsidies of education would also cease to exist, as they may indirectly influence the supply and demand for research on education.

There are at least two separate defenses of a laissez-faire approach. The first is a rather unique mix of Enlightenment faith in the freedom of inquiry and skepticism of government. The general thrust of the argument is that government acts are inherently coercive, and that coercive acts are inherently bad. Any government act that influences how researchers organize their work extends the scope of government's control over our thoughts and hence our identities (Baez and Boyles 2009). Thus, all government influence should be avoided.

The logic behind the laissez-faire approach reproduces the general logic of how criticism-driven markets ideally operate. This holds that the criticism of self-interested rivals is the best mechanism for distributing capital. In the event that this mechanism fails to generate satisfactory outcomes, such failure will either be eventually corrected or merely tolerated. On this view, any attempt to meet market failures with subsidies or regulations would inevitably create more distortion than it solves.

However, the laissez-faire approach is enmeshed in a conceptual difficulty, namely, the fact that a failure to act can itself be interpreted as an act (for a vivid proof, see Unger [1996]). If the federal government completely disengages from education research, it is likely that much longitudinal (international 
and comparative) and large-scale research would cease to be possible. By removing the conditions for the possibility of such research, the government can effectively limit the kinds of questions researchers are capable of investigating, such as the differences in pedagogy across districts, states, and countries, long-term trends in student achievement, the relationship between education and health, and so forth. Thus, the choice not to fund such research can be seen as just as much an act of control as the choice to fund it.

In addition, there are many "back-door" ways in which government influences education research. National, state, and local governments subsidize the production and consumption of research in a number of ways, from the paying of faculty salaries to the creation of research clearinghouses. Whether or not, for instance, public schools exist is likely to influence the demand for research on public schools. The presence or not of a large military is likely to influence the demand for research on military aptitude. There are countless ways in which government actions in other areas influence the demand and supply for information about education. Thus, the laissez-faire approach is conceptually incompatible with our understanding of modern government.

Let us assume that the research market will, with greater or lesser frequency, fail from time to time. The question is whether government interventions tend to correct or exacerbate such failures. I focus on one particular intervention strategy - setting standards and then subsidizing research that meets those standards.

The logic behind the standards-based approach is as follows: First, the qualities that are to be desired in research are determined a priori. Second, standards are aligned with these qualities. Third, incentives are created to produce or consume research that aligns with these standards. If successful, research activity that has the qualities that are desired will be increased. Further, the utility gained from this increase will outweigh the utility lost due to opportunity costs and from the absence of criticism from those who are excluded as a result of not meeting the standard.

This can be done in part by concentrating capital on agents whose durable dispositions align with the federal government's understanding of relevance and rigor. This capital can be leveraged into research that produces highly visible publications. Barbara Schneider (2009) argues that publications are the "currency" of academia, being the means of acquiring "prestige, recognition, and access to research funding" (83). She extends the arguments of Robert Merton (1968) and Arthur Diamond (1986) on the connection between citations and the ability to win tenure, promotion, and influence. These victories can be additive, giving researchers "cumulative advantage" (Merton 1988). Thus, by concentrating capital on researchers whose dispositions are aligned with government standards, government can begin a process that may perpetuate itself long after the initial investment. 


\section{Political Economy of Education Research}

Producers and policy makers often argue that some group is not consuming enough education research or enough of the right kinds of education research. By converting the products of agents who are aligned with federal interests into a form that is more marketable to influential consumers, the federal government can increase the rates of return to the agent producing the research. This both increases the profitably of such research and lowers the costs of consuming it. The conferring of publicity onto certain research projects also confers capital to those who produce them. This capital can then be reinvested into additional research that can further strengthen one's position relative to his or her competitors.

An alternate strategy is to attempt to partially shut down the production of research that does not serve federal priorities. For instance, the federal government can make it impossible for states to purchase curricula without also purchasing (for instance) a randomized control trial to demonstrate their effectiveness. This can virtually shut down the production of large-scale evaluations that use alternative methodologies.

The standards-based approach can fail in at least two ways. First, it can fail if it overcorrects and diverts resources from more productive kinds of inquiry. This overcorrection can generate the academic equivalent of a "bubble." That is, the perceived value of certain research questions, topics, or methods may be higher than the actual value, thus attracting an undeserved level of investment. Second, it can fail if the absence of criticism from those outside of the standard causes a decrease in quality that is more than the increase gained by adherence to the standard. This can happen when researchers are less focused on withstanding the criticism of others and more focused on compliance.

Perhaps the greatest danger to the standards-based approach is that it narrows the range of criticism by disarming research that is out of compliance with established protocols. The result is that researchers who are in compliance no longer have to face the critique of rivals whose own self-interest depends on subjecting these products to intense scholarly scrutiny. The removal of this pressure may "make researchers compliant rather than creative" (Mortimore 2002, 17). Rather than strengthening the incentives for high-quality research, standards may unintentionally weaken them by making it easier to get by without facing a full vetting by the research community.

This raises problems with the ways that standards limit access to the research marketplace. The first is fairness. Standards put some individuals at the center while pushing others to the periphery. Others have written at length about how federal policy has altered the population involved in the production of education research (Lagemann 2000; Travers 1983; Vinovskis 2009; Warren 1974). The marginalization of parts of the research community (as well as other communities) from the production and consumption of knowledge is an 
ethical and political issue. For instance, the choice to concentrate subsidies on research on topics of administration, finance, and organizational leadership places policy makers and administrators at the center. It addresses the challenges and needs they must meet in order to do their jobs. Conversely, research on behavioral management or curriculum design more directly address the challenges that teachers face. A teacher may consume such research not just as an idle curiosity, but as a way of improving his or her practice. Similarly, research on the effects of school choice, tracking, and neighborhood and peer effects may be more likely to draw parents into the research market, as it addresses factors over which they may have some influence.

The ethical problem forks into two epistemological problems. If "relevance" is part of what determines one's estimation of the quality of a product, and if one can expect one to determine that a product is relevant to the extent that it meets one's own needs, then one might expect that this judgment of quality is highly dependent on who is doing the judging. Each act of exclusion runs the risk of weakening the "unrelenting criticism" through which science transcends idiosyncratic interests and gains a degree of objectivity. Attempts to increase rigor and relevance that are predicated on concentrating capital on a select breed of producers or consumers must provide some evidence that this risk has been mitigated.

The standards-based approach seems likely to fail to satisfy any number of theoretical requirements for a satisfactory account of inquiry. Three complementary frameworks relevant to this article are worth mentioning - those of Pierre Bourdieu, Elizabeth Anderson, and James Bohman. Bourdieu's notion of open, unrelenting criticism is strikingly similar to recent work in social epistemology and deliberate theory. For instance, Elizabeth Anderson (2006) argues convincingly that no centralized body - whether it is a research agency (such as IES) or a professional organization (such as AERA) - can effectively distribute the resources necessary for knowledge production and consumption. The problem lies in the basic fact that the relevant information is scattered across a group of "epistemically diverse knowers" (Anderson 2006, 8). Anderson argues that it is not simply diversity that produces better results, but the open, inclusive, wide-ranging criticism that diversity makes possible. Thus, inquiry into common problems is likely to be epistemologically stronger when there are fewer barriers to participation. James Bohman (2006) similarly argues that in matters of public concern, the rationality of centralized decisions is "easily overwhelmed by deep conflicts and entrenched problems" (187). The task of trying to keep false or unproductive opinions out of the debate is unlikely to succeed. However, given sufficient openness and incentives for deliberative engagement, false or unproductive opinions are more likely to be exposed as such.

The criticism-driven approach seeks to encourage rather than restrain the 


\section{Political Economy of Education Research}

characteristics unique to criticism-based markets. Namely, rather than equating quality with what meets an antecedently articulated standard, it holds that the best marker of quality is the ability to withstand the criticism of wellarmed rivals.

Aspects of the criticism-driven approach have already been described. There are two main strategies, one negative and one positive. On the negative side, the criticism-driven approach entails removing the extent to which research capital is distributed on the basis of one's success in marketing, lobbying, compliance with standards, nepotism, or other noncritical activities. While the negative strategy can remove some of the opportunities to win federal support without facing extensive criticism, it is limited. There is little that governments can do to regulate how publishers market their products or whether friendly colleagues give each other favorable time slots at academic conferences. Further, there is no sharp line between "marketing" and "dissemination." In fact, one might argue that researchers have a public duty to be more, rather than less, active in pushing their products.

Thus, it is the positive strategy that must do the most work. This entails increasing the incentives to pursue capital through the criticism of one's rivals. The gains to be had by this process must be significant enough to shift some portion of an agent's investments away from other activities and toward these critical activities. Tenure committees might do this by giving significant weight to the applicant's success in having her or his research published in peerreviewed journals, as well as inviting other rivals to appraise her or his work.

The shortcomings of current ways of engaging potential and actual critics are well known. For instance, the process of peer review is doubly vulnerable to corruption. First, authors can exploit the fragmentation of the research market to limit the range of potential critics. Many producers of education research feel that there is a very small group of individuals who are competent to assess the value of their own work. Further, many might hold that these relations are not reciprocal. For instance, a researcher may feel competent to judge the work of another researcher without feeling that that other researcher can competently judge her own work. Second, those responsible for publishing the work of authors are frequently accused of conservative bias, so much so that Elliot Eisner (2002) has argued that peer review poses a grave threat to creativity and innovation.

Prioritizing a criticism-driven approach need not entail rejecting standards. The key question regarding the standards-driven versus criticism-driven approaches is in the logical priority - do we make the standards subject to criticism, or criticism subject to standards? The main contention that this article offers is that the latter approach is unsustainable and more open to degeneration. Thus, if a compatabilist position is what is to be desired, it must still be one that places criticism as logically prior. The standards should emerge 
as temporary resting points that allow debate to continue on other topics. Standards are the fruit rather than the root of scientific inquiry. They are the product of scientific growth and contain the seeds for its continuation. Research does not advance by adherence to standards; standards become more useful by the advances in research.

The critical approach gives a more strenuous assessment of the quality of research. Producers are subject not just to a checklist of standards but must anticipate what others think, including those who think with a checklist. It is thus likely that the critical approach captures all of the benefits of the standards approach while providing incentives to do even better.

\section{Conclusion}

This article has given an account of rigor as a matter of the process by which capital is distributed, rather than conformity to antecedent protocols or moral positions. Rigorous research is that which answers the well-armed criticism of self-interested rivals. This understanding of rigor is superior to others in that (1) the norms that govern it are themselves improvable, rather than static; (2) it is most likely to draw on the epistemic diversity of all those engaged in research; and (3) it usefully directs the banal incentives that influence education research toward public ends.

If researchers know that they will face widespread scrutiny, they may be forced to think hard about the assumptions and commitments involved in their work. This may also go a long way toward meeting the accusations of a lack of relevance. Confronting self-interested criticism from people who find their own research much more relevant forces researchers to more clearly articulate and defend the significance of their work and to do so in a way that is understandable and persuasive to those beyond their niche. Furthermore, it may do so in a more effective way than by giving "users" of education research more direct control over the ways in which it is conducted (an approach usefully dissected by Gorard [2002]).

While the article argues for broad principles to guide the allocation of resources, it does not offer any conclusions as to what this allocation will be. As with research itself, this article focuses on the process rather than the results. While this is the case, such a process is unlikely to support some sorts of results - for instance, radical exclusion of marginalized voices. If such marginalization of individuals, and the subsequent degeneration of quality in the research market, is to be prevented, those vested with the power to distribute capital - such as higher degrees, grants, publications, presentations, students, prestige, tenure, promotion, and panel membership - will need to place the 


\section{Political Economy of Education Research}

sustained criticism of diverse, well-armed, self-interested rivals at the center of their activity.

This may require a number of changes. Editorial boards, tenure and promotion committees, and review panels may need to rebalance membership between specialists and those from other areas. Specialists are required to handle highly technical and nuanced claims - such as whether a historian's take on the origins of summer vacation includes all relevant sources, or whether a psychologist is making use of the most sophisticated instruments available, or whether a philosopher is providing a defensible interpretation of a given thinker. However, the problem is that the people close enough to the area of research to make such specialized judgments may lack the distance to make more general, and perhaps more important, judgments. In addition, the selfinterest of fellow specialists may overlap too much with the self-interest of the person being judged, creating a perverse incentive to give it a positive judgment. Thus, rigor may require not only criticism from fellow specialists but from those who enjoy a degree of intellectual distance.

This intellectual distance can have a number of dimensions. It can be people who share the same area of research but draw on different disciplinary traditions. It can be people who share the same disciplinary orientation but apply it to different topics. In either case, the value of the topic and the disciplinary approach are no longer simply assumed but become a possible subject of inquiry. The composition of these panels and editorial boards is by necessity imperfect - there is no panel large enough to represent every possible viewpoint. But adding just one member may be a significant improvement. The distance she or he brings may even help others rethink some of the assumptions made by a proposal. The intellectual distance that separates education researchers from each other, often bemoaned as "fragmentation" or "disjointedness," might be a resource rather than an obstacle.

What holds for the review panels of journals also holds for the publications that appear in journals. While there are a number of journals that have a rather broad mission (such as American Fournal of Education, Teachers College Record, and the American Educational Research Fournal), researchers frequently seek outlets that have a far narrower audience. This article does not mean to imply that specialist journals should not exist. But they must continue to demonstrate the usefulness of the specialism to the broader community. Otherwise, they devolve into scholasticism and irrelevance. For instance, it may not be enough that a given article advances our understanding of what John Dewey really meant in a given essay. One needs to also show that this is something worth understanding. For a journal focused on measurement, it is not enough to show that a given article advances the precision of some measurement, but how this precision may actually help with a problem that other people interested in education might find compelling. Specialist journals should be a venue 
for specialists to engage the world and to have a voice, not enclaves where they can retreat from broader scrutiny or social problems.

Academic conferences are another key venue for exchanging research for social, cultural, and political capital. Hence, the extent to which this capital is distributed on the basis of criticism is worthy of attention. The larger conferences, such as those of the American Education Research Association, are double edged. The proliferation of divisions, sections, and special interest groups allows for focused discussion on carefully delimited questions. However, even these groups could benefit by integrating those who have different interests and thus perhaps some degree of distance. The amount of distance desired might vary. The Paulo Freire special interest group may not need to go so far as inviting researchers who study performance pay (not that this would be a total waste of effort). They might benefit just by bringing in educational philosophers working in different traditions. Small steps may be significant, allowing researchers' voices to reach a broader audience, rather than remaining sealed off behind the closed doors of cramped conference rooms.

Doctoral education, some of which is subsidized by the federal government, gives another opportunity for reform. Federal funds for many doctoral programs have been tied to the training of researchers who are committed to research that uses randomized control field trials. On the one hand, these grants recognize how few current researchers there are who are capable of managing field experiments. However, it is not at all clear that field experiments can form the sole basis of a productive career. Such training programs may need to be more broadly focused, making sure that students defend not just the integrity of their research designs but the integrity of their conceptual and theoretical frameworks, and understand the place of their work in relation to other methodological approaches.

An important question remains unanswered: What private incentives are there for researchers to reform the current system so as to place criticism at the center of the process of distribution? Do the reforms suggested in this article depend on selfless agents, or can they function even if the research economy is dominated by self-interests? While the public may benefit from reforms that give criticism a central role in the distribution of capital, it is less obvious that individual researchers will see comparable private benefits. Those who fare well in the current setup, in which debate is limited to a very narrow range of like-minded peers, may be reluctant to change.

The answer depends to a large extent on the confidence researchers have in their own work. They may suspect that their work would fail to earn approval from those outside of their niche. If so, then a criticism-driven research economy looms as a threat to their private well-being. However, those who feel that they can communicate the relevance and rigor of their work to a broader audience may be drawn in by the incredible potential of the crit- 


\section{Political Economy of Education Research}

icism-driven research economy. Getting one's work in the hands of a broader audience might help one cultivate expanded professional networks and achieve greater impact both in scholarly literature and in the greater society. This in turn can help one move to a more prestigious university, earn tenure and promotion, and negotiate a higher salary. Thus, a reformed research economy may be good not just for society at large but for the researchers who make it function.

This article has identified the main political and economic dimensions of education research markets, the ways in which these markets can function or fail, and the ways in which governments can respond. The main argument is that the best research policies will place criticism at the center of the research market, perhaps by way of some of the suggestions mentioned above. These suggestions are tentative, as should be any suggestion about the policy implications of political philosophy or social theory, all the more so when the topic is as vexing as education. The criticism-based approach is unlikely to solve any problems in their entirety, but it may do a better job of managing them than its main rivals. Given the severity of the charges against education research, it is hard to imagine that the research economy would not be improved if we came to expect researchers to be responsive to a much wider range of conceptual, theoretical, and empirical criticism.

\section{References}

American Education Research Association. 2006. "Standards for Reporting on Empirical Social Science Research in AERA Publications." Educational Researcher 35 (6): 33-40.

American Education Research Association. 2008. "Definition of Scientifically Based Research,” http://aera.net/uploadedFiles/Opportunities/DefinitionofScientificallyBasedResearch.pdf.

$\rightarrow$ American Education Research Association. 2009. "Standards for Reporting on Humanities-Oriented Research in AERA Publications." Educational Researcher 38 (6): 481-86.

$\rightarrow$ Anderson, E. 2006. "The Epistemology of Democracy." Episteme 3 (1-2): 8-22.

Atkinson, E. 2000. "In Defence of Ideas, or Why 'What Works' Is Not Enough.” British Fournal of Sociology of Education 21 (3): 317-30.

Baez, B., and D. Boyles. 2009. The Politics of Inquiry: Education Research and the "Culture of Science." Albany: SUNY Press.

Biddle, B. J., and L. Saha. 2002. The Untested Accusation: Principals, Research Knoweledge, and Policy Making in Schools. Westport, CT: Ablex.

Biesta, G. 2007. "Why 'What Works' Won't Work: Evidence-Based Practice and the Democratic Deficit in Educational Research." Educational Theory 57 (1): 1-22.

$\rightarrow$ Bohman, J. 2006. "Deliberative Democracy and the Epistemic Benefits of Diversity." Episteme 3 (1): 175-91.

Bourdieu, P. 1986. "The Forms of Capital." In Handbook of Theory and Research for the Sociology of Education, ed. J. Richardson. New York: Greenwood. 
Bourdieu, P. 1991. "The Peculiar History of Scientific Reason.” Sociological Forum 6 (1): $3-26$.

$\rightarrow$ Cannela, G. S., and Y. S. Lincoln. 2004. "Claiming a Critical Public Social Science: Reconcepualizing and Redeploying Research." Qualitative Inquiry 10 (2): 298-309.

$\rightarrow$ Clair, R. S., and A. Belzer. 2007. "In the Market for Ideas: How Reforms in the Political Economy of Educational Research in the US and UK Promote Market Managerialism." Comparative Education 43 (4): 471-88.

Cremin, L. 1976. Public Education. New York: Basic.

$\rightarrow$ Crossley, M. 2008. "The Advancement of Educational Research in Small States." Comparative Education 44 (2): 247-54.

$\rightarrow$ Diamond, A. 1986. "What Is a Citation Worth?" Fournal of Human Resources 21:200215.

Easton, D. 1965. A Framework for Political Analysis. Englewood Cliffs, NJ: Prentice-Hall. Education Sciences Reform Act of 2002. 2002. Public Law 107-279.

Eisenhart, M., and L. Towne. 2003. "Contestation and Change in National Policy on 'Scientifically Based' Education Research.” Educational Researcher 32 (7): 31-38.

Eisner, E. W. 2002. The Educational Imagination: On the Design and Evaluation of School Programs (3rd ed.). Upper Saddle River, NJ: Prentice-Hall.

Feuer, M. 2006. Moderating the Debate: Rationality and the Promise of American Education. Cambridge, MA: Harvard University Press.

Goldhaber, D., and D. Brewer. 2008. "What Gets Studied and Why: Examining the Incentives That Drive Education Research.” In When Research Matters: How Scholarship Influences Education Policy, ed. F. Hess. Cambridge, MA: Harvard University Press.

$\rightarrow$ Gorard, S. 2002. "Political Control: A Way Forward for Educational Research?" British Fournal of Educational Studies50 (3): 378-89.

Hargreaves, D. H. 1996. Teaching as a Research-Based Profession: Possibilities and Prospects. London: Teacher Training Agency.

Henig, J. R. 2008. Spin Cycle: How Research Is Used in Policy Debates: The Case of Charter Schools. New York: Russell Sage Foundation: Century Foundation.

Hess, F., ed. 2008. When Research Matters: How Scholarship Influences Education Policy. Cambridge, MA: Harvard University Press.

Hillage, J., R. Pearson, A. Anderson, and P. Tamkin. 1998. Excellence in Research on Schools. London: Department for Education and Employment/Institute for Employment Studies.

Johanningmeier, E. V., and T. R. Richardson. 2008. Educational Research, the National Agenda, and Educational Reform: A History. Charlotte, NC: IAP-Information Age Publishing.

Lagemann, E. C. 2000. An Elusive Science: The Troubling History of Education Research. Chicago: University of Chicago Press.

$\rightarrow$ Loewenberg Ball, D., and F. Forzani. 2007. "What Makes Education Research 'Educational"'? Educational Researcher 36 (9): 529-40.

Merton, R. K. 1968. Social Theory and Social Structure. New York: Free Press.

$\rightarrow$ Merton, R. K. 1988. "Matthew Effect in Science, II: Cumulative Advantage and the Symbolism of Intellectual Property." Isis 79 (4): 606-23.

$\rightarrow$ Mortimore, P. 2000. "Does Educational Research Matter?" British Educational Research Fournal 26 (1): 5-24.

National Research Council. 2002. Scientific Research in Education. Washington, DC: National Academies Press.

National Research Council. 2003. Strategic Education Research Partnerships. Washington, DC: National Academies Press. 


\section{Political Economy of Education Research}

National Research Council. 2004. Advancing Scientific Research in Education. Washington, DC: National Academies Press.

No Child Left Behind Act of 2001. 2002. Public Law 107-110.

Reading Excellence Act. Title VIII of the Departments of Labor, Health, and Human Services and Education, and Related Agencies Appropriations Act, 1999 of the Omnibus Appropriations Bill. 1999. Public Law 105-277.

Reynolds, D. 1998. Teacher Effectiveness: Better Teachers, Better Schools. London: Teacher Training Agency.

Schneider, B. 2009. "Assessing Quality in Education Journals." In Education Research on Trial: Policy Reform and the Call for Scientific Rigor, ed. P. Walters, A. Lareau, and S. Ranis. New York and London: Routledge.

Spillane, J. 2004. Standards Deviation: How Schools Misunderstand Education Policy. Cambridge, MA: Harvard University Press.

Tooley, J. 1998. Educational Research: A Review. London: Office for Standards in Education/HMSO.

Travers, R. M. W. 1983. How Research Has Changed American Schools: A History from 1840 to the Present. Kalamazoo, MI: Mythos.

Unger, P. 1996. Living High and Letting Die: Our Illusion of Innocence. New York: Oxford University Press.

Vinovskis, M. 2009. From a Nation at Risk to No Child Left Behind: National Education Goals and the Creation of Federal Education Policy. New York: Teachers College, Columbia University.

Warren, D. R. 1974. To Enforce Education: A History of the Founding Years of the United States Office of Education. Detroit: Wayne State University Press. 